\title{
A atividade investigativa na elaboração e análise de experimentos didáticos
}

\section{RESUMO}

Evelyn Jeniffer de Lima Toledo jeniffer.toledo@gmail.com

$\frac{0000-0003-4266-4377}{\text { Universidade Federal de São Carlos, São }}$ Paulo, Brasil.

\section{Luiz Henrique Ferreira} ferreiraufscar@gmail.com

0000-0002-5737-9723

Universidade Federal de São Carlos, São Paulo, Brasil.

\begin{abstract}
A atividade experimental pode ser um excelente recurso para motivar e ampliar o espectro de aprendizagem, mas para isso deve trazer consigo mais do que cores e transformações espetaculosas, deve auxiliar o aluno a assumir seu papel de agente do próprio aprendizado estimulando a autonomia, a reflexão, e o senso crítico. A metodologia investigativa é consensualmente a mais indicada, resultando em um maior ganho em habilidades procedimentais e cognitivas por exigir que o aluno a partir de uma situação problema elabore uma hipótese, planeje uma metodologia, obtenha dados e os coloque sob julgamento, confirmando-a ou rejeitando-a. Sob a luz das qualidades da atividade investigativa que este trabalho se propôs a demonstrar como é possível, através de princípios gerais, elaborar e testar modelos experimentais evitando erros básicos. Os experimentos utilizados como modelo pretendiam simular o efeito estufa e devido à ausência de critérios foi constatado que nenhuma das atividades obteve sucesso.
\end{abstract}

PALAVRAS-CHAVE: Efeito estufa. Experimentos. Atividade investigativa. 


\section{INTRODUÇÃO}

Compreender o universo é interesse antigo da humanidade e o processo para esta compreensão vem se desenvolvendo com o passar dos séculos. Para Aristóteles a natureza era passível de entendimento através da observação natural reflexiva, ou seja, era necessário que o homem observasse a natureza e fazendo uso da razão a descrevesse e inferisse teorias. Essa visão de uma ciência teórica reflexiva pautada na observação sem instrumentos inanimados de medição permeou o mundo por muito tempo sendo superada, principalmente, através de 3 cientistas: Francis Bacon, Descartes e Galileu (GIORDAN, 1999). Apesar do destaque, historicamente atribuído a estes, eles não são os únicos responsáveis pelas mudanças de concepções na produção do método cientifico.

As pessoas não constroem conhecimentos sozinhas a partir do nada. Nascemos todos em um cenário epistemológico onde já existe muito conhecimento e variados métodos para sua produção, ampliação e aperfeiçoamento (Chalmers, 1994).

Chalmers (1994) destaca que apesar da mudança e deste método ser adotado até os dias atuais não podemos considerar a física de Galileu um avanço em relação à física de Aristóteles, pois para isso seria necessário considerar que existe um padrão capaz de explicar ambas as teorias, ou seja, deveria haver um método universal da ciência.

A contribuição de Francis Bacon, no século XVII, para elaboração do método científico veio da sua percepção acerca da necessidade de se substituir uma simples observação, como era feita por Aristóteles, por uma observação efetuada em circunstâncias padronizadas através de procedimentos protocolados. Assim, idiossincrasias da percepção humana são minimizadas (CHALMERS, 1994).

\footnotetext{
Sempre que passo a um novo experimento de qualquer sutileza (embora em minha opinião esteja correto e eu o aprove), acrescento uma explicação clara sobre como eu o realizei, pois os homens, sabendo exatamente como cada argumento foi construído, poderão ver se há algum erro ligado a ele e empenhar-se em criar provas mais confiáveis e mais requintadas, se tais provas puderem ser encontradas. Finalmente, interponho por toda parte admoestações, escrúpulos e cautelas a serem tomadas, com um religioso cuidado em eliminar, reprimir e até exorcizar todos os tipos de fantasmas (BURTT, 1967, p.21 apud CHALMERS, 1994).
}

Francis Bacon fundamentou a ciência indutivista em que observações e coletas de dados sobre o particular, contextualizado no experimento, leva a elaboração de enunciados mais genéricos que podem adquirir a força de lei ou teoria dependendo do grau de abrangência do problema em estudo e do número de experimentos concordantes (GIORDAN, 1999).

Descartes, por outro lado, seguindo uma direção inversa propôs que as leis gerais dariam origem a teorias individuais e este caminho seria preenchido por eventos experimentais, estava constituída a Dedução (GIORDAN, 1999).

A Galileu coube o papel de legitimar a necessidade da experimentação na construção do conhecimento cientifico. Galileu não apenas percebeu a necessidade de um método padrão para possíveis reproduções como considerou que seria necessário criar situações artificiais especialmente planejadas com o 1994). 
O Experimento então foi assumindo um papel privilegiado na atividade cientifica, sendo Bacon, Descartes e Galileu os cientistas considerados fundadores da ciência moderna por substituir a observação baseada nos sentidos por uma experimentação através de instrumentos, minimizando a subjetividade.

No sistema escolar, embora haja controvérsias, Justus Von Liebig é considerado precursor do uso do laboratório no Ensino de Química. Em uma das suas atividades divulgadas, seus alunos recebiam um frasco com uma substância desconhecida e quando estas eram identificadas, Lidebeg considerava os alunos aptos a trabalharem na pesquisa de problemas individuais. No sistema escolar brasileiro, entre 1964 e 1984, a atividade experimental tinha um caráter predominantemente demonstrativa e expositiva (SUART, 2008), enquanto hoje, século XXI, embora hajam metodologias mais interessantes como a investigativa, prepondera a atividade experimental protocolada, em que o aluno segue instruções na execução do experimento sendo destituída a necessidade de pensar, de tomar decisões e de fazer uso de sua criatividade, o objetivo principal é obter um resultado pré-determinado (FILHO, 2000). Práticas protocoladas costumam resultar em punições ao aluno caso este obtenha um resultado diferente do desejado o que pode gerar uma conduta antiética do discente, como relata Borges (2002) ao destacar uma pesquisa realizada por Nott e Wellington (1997). Nesta pesquisa, licenciandos em ciências afirmaram que já haviam falseado ou alterado dados para que o experimento gerasse o resultado correto.

Essa preocupação com o resultado do experimento pode proporcionar um estereótipo sobre a atividade científica por apresenta-la como uma estrutura rígida em que há um conjunto de etapas a serem seguidas. Além desta visão deturpada da ciência, Pérez et al. (2001) destaca outras seis possíveis deformações:

1) Ciência neutra em que qualquer observador, independente de suas concepções teóricas, irá observar e inferir o mesmo;

2) Teorias surgem do nada, pois são retiradas de seu contexto sendo omitido não apenas de onde se originaram, mas também sua evolução e dificuldades;

3) Teorias fragmentadas;

4) Conhecimento acumulativo sendo desconsideradas as crises, remodelações e revoluções;

5) Conhecimento como obra de grandes gênios ou como uma atividade simples próxima ao senso comum;

6) O conhecimento é construído isolado da sociedade e o cientista, em sua torre de marfim, esta acima do bem e do mal.

Apesar das possíveis deformações que podem ser oriundas da experimentação e também da aula teórica, muitos professores enxergam a atividade prática como uma tábua de salvação dos processos de ensino e aprendizagem, o que encontra respaldo por parte de alguns pesquisadores. Entre as razões destacadas pelos docentes para realiza-las estão: 1) estimular o interesse (motivação); 2) ensinar habilidades de laboratório; 3) aumentar a aprendizagem; 4) introduzir ao método científico e desenvolver o raciocínio; 5) desenvolver "atitudes científicas" (HODSON (2005) apud STUART (2008)); 6) ilustrar as aulas teóricas; 7) ensinar uma teoria não incluída nas aulas; 8) treinar a 
interpretação de dados experimentais e 9) incentivar a pesquisa (BENITE; BENITE (2009)).

Além da visão distorcida acerca do papel da experimentação, citada por Pérez et al. (2001), na sala de aula muitos professores acreditam em uma equidade com a função do experimento na ciência ( BENITE; BENITE, 2009) e partem de um pressuposto que inicia seu equivoco nos objetivos (ATAIDE; SILVA, 2011) pois enquanto a experimentação na sala de aula visa um processo pedagógico estimulando a confiança e ensinando sobre a natureza do conhecimento cientifico (BENITE; BENITE, 2009), o principal objetivo da ciência acadêmica é produzir novos conhecimentos. Além disso, os cientistas contam com uma infra-estrutura (intelectual e física), em geral, mais sofisticada (MUNFORD; LIMA, 2007). Essa crença de que atividade experimental na sala de aula seria uma reprodução da pesquisa científica e que, portanto o aluno teria um ganho cognitivo significativo foi sendo perpetuada. Assim, o experimento, mesmo quando não realizado pelo aluno, mas pelo professor, se torna uma espécie de Santo Graal da educação, capaz de resolver todos os problemas de ensino, motivando e ampliando o espectro de aprendizagem. O professor, ingênuo, acredita que através da experimentação formará jovens cientistas, que os alunos poderão validar a teoria, verificar os fatos estudados, encontrar fatos e chegar a seus princípios por investigação. Porém, nem mesmo a motivação ocorrerá de forma absoluta, pois enquanto de um lado há alunos que sentem prazer com a prática há do outro lado os que têm aversão (HODSON, 1994 apud STUART, 2008; GONÇALVES; MARQUES ,2012). Alguns alunos citam que o laboratório é uma perda de tempo, tempo este que segundo eles poderia ser aproveitado estudando (THOMAZ, 2000). Às vezes a motivação constatada é apenas resultado do contraste com a aula tradicional por acrescentar cor, curiosidade, por ser um evento alheio à rotina (BORGES, 2002), a mesma reação poderia ser esperada para outras atividades como uma visita técnica, um show de ciência, um teatro. Portanto, caso a empolgação se dê basicamente pela novidade, se for sempre executada perde seu caráter motivador. Quanto ao desenvolvimento de habilidades, ele está diretamente vinculado à natureza do experimento (SUART, 2008) e deste modo não há garantia de aprendizagem (SUART, 2008; BORGES, 2002).

Apesar de todos esses apontamentos, a simples presença da atividade experimental na sala de aula vem sendo correlacionada como uma evolução no sistema de ensino, o que é evidenciado pelas propagandas de várias escolas que fazendo uso de fotos de laboratórios aludem uma certa superioridade. Porém, como já foi discutido, apenas a presença de experimentos não significa qualidade de ensino, assim como a disponibilidade de equipamentos, laboratórios e reagentes. Uma aula teórica pode ser qualitativamente superior a uma aula experimental (GIOPPO; SCHEFFER; NEVES, 1998). O que confere qualidade a uma aula, seja ela experimental ou teórica, é o envolvimento com a busca de soluções para as questões propostas (BORGES, 2002).

Apesar da visão favorável dos professores acerca da atividade experimental na sala de aula muitos não fazem uso dela e alegam diversas razões como: 1) não haver atividades já preparadas para o professor; 2) falta de recursos para compra de componentes e materiais de reposição; 3) falta de tempo do professor para planejar; 4) laboratório, quando existente, fechado e sem manutenção (BORGES, 2002); 5) excessivo número de alunos na sala de aula; 6) formação inadequada; 
7) pouca bibliografia para orientá-los; 8) falta de laboratorista (LABURU, BARROS, KANBACH, 2007). As justificativas fundamentadas na ausência de recursos, embora recorrente, pouco se sustenta, pois a presença de atividades experimentais de baixo custo em revistas educacionais é frequente (SILVA et al., 2009).

Assim, esse conflito sobre a atividade experimental na sala de aula está mais relacionado à sua natureza do que a sua presença ou ausência. O significado do termo "natureza" nada tem a ver com a teoria com que ele se correlaciona e sim com a forma com que é mediado na disciplina. Experimentos de natureza "receita de bolo", onde um protocolo é entregue aos alunos que assumem a função, exclusivamente, de executá-lo e obter resultados pré-determinados, raramente vão derivar ganhos significativos.

\begin{abstract}
(...) uma experiência que não seja realizada pela própria pessoa, com plena liberdade de iniciativa, deixa de ser, por definição, uma experiência, transformando-se em simples adestramento, destituído de valor formador por falta de compreensão. (JEAN PIAGEN apud GIOPPO et al. (1998)).
\end{abstract}

A literatura indica que experimentos de natureza investigativos são mais bem sucedidos, pois esta abordagem não apenas se qualifica como motivadora, mas está correlacionada com um ganho em habilidades cognitivas de alta ordem (SUART, 2008). Ela estimula o desenvolvimento do raciocínio, do pensamento crítico por exigir que o sujeito trabalhe a observação, formulação de hipóteses, elaboração de um plano de trabalho, montagem de um aparato experimental, colete dados, discuta consigo e/ou com os pares, chegue a conclusões e comunique seus resultados (ZOMPERO, LABURU, 2011). Goi e Santos (2008) argumentam que o uso de atividades investigativas resultou em uma melhora na comunicação por alunos que, durante as aulas, não participavam.

Apesar da atividade investigativa ser consensualmente indicada por pesquisadores de ensino como qualitativamente superior (SUART, MARCONDES, 2009), ela ainda vem sendo pouco utilizada pelos professores e autores de material didático. Assim, o objetivo deste trabalho é através de uma análise crítica mostrar como é possível perceber erros em experimentos através de seus princípios gerais e então incentivar seu uso evitando equívocos básicos.

Os experimentos analisados se auto intitulam simuladores do efeito estufa. Este assunto foi escolhido porque apesar de estar constantemente presente nas discussões, tanto na mídia quanto no sistema de ensino, não faz parte da ciência normal segundo os pressupostos de Kuhn (1998), já que devido a suas controvérsias não há uma concordância da comunidade acadêmica e, portanto é de uma enfática riqueza para a discussão da atividade investigativa.

\title{
METODOLOGIA
}

Foram pesquisados na literatura científica e também na literatura informal experimentos que simulassem o efeito estufa. Foram usadas como palavras chave "efeito estufa" e "experimento" sendo verificados os 100 primeiros links do Google e todos os do Google Acadêmico e Web of Science (Greenhouse, Experiment). Dos experimentos localizados foram selecionados os que, apesar de conterem erros sistemáticos, conversam entre si permitindo que a discussão se dê de forma gradual, mas ao mesmo tempo progressiva a nível teórico. 


\section{RESULTADOS}

Foram selecionados 8 experimentos estando todos eles na forma de uma atividade prática tradicional, ou seja, como um protocolo que exige do aluno apenas habilidades manuais na montagem do aparato experimental.

A elaboração de uma metodologia para representar um modelo seja do efeito estufa ou outro qualquer inicia-se em uma situação problema, portanto o primeiro passo é realizar uma pergunta. Assim, ao invés de solicitar que os alunos simulem o efeito estufa, o professor deveria elaborar uma questão, como por exemplo:

- Os gases atmosféricos são responsáveis pela temperatura média na Terra?

- O aumento na concentração do $\mathrm{CO}_{2}$ na atmosfera contribui para o aquecimento global?

Tendo em mente o questionamento desejado, o segundo passo é o domínio dos conceitos envolvidos, pois caso hajam concepções equivocadas todo procedimento a posteriori trará consigo erros sistemáticos.

Portanto, neste trabalho, se torna necessário definir o Efeito Estufa:

Segundo a teoria do Efeito Estufa, dentre as radiações emitidas pelo sol chega à atmosfera da Terra luz U.V (Ultravioleta) e UV-vis (Ultravioleta visível) que ao serem absorvidas pela superfície terrestre podem ser convertidas em infravermelho (I.V.) que então será irradiado. Na atmosfera, caso o I.V. encontre moléculas com momento dipolo induzido ou permanente diferente de zero ele será absorvido e posteriormente emitido em todas as direções. Esse processo resulta em um maior tempo de permanência da radiação na atmosfera mantendo a mesma aquecida. A partir desta teoria cientistas induziram que o aumento na concentração dos gases capazes de absorver I.V. resultaria em um aquecimento ainda mais intenso, já que a probabilidade da radiação emitida ser absorvida se tornaria maior. Um esquema dos fatores que atuam no efeito estufa pode ser visualizado na Figura 1.

Figura 1- Representação dos processos de incidência de radiação ultravioleta com posterior emissão de radiação infravermelha sendo absorvidas por moléculas de $\mathrm{CO}_{2}$ e $\mathrm{H}_{2} \mathrm{O}$.

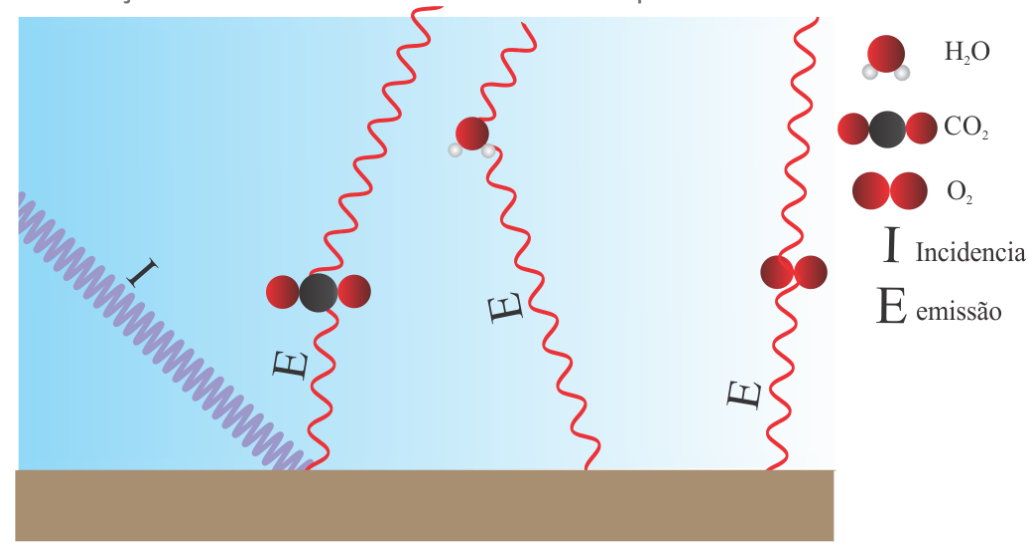


Em posse dos conhecimentos teóricos mínimos necessários, o segundo passo é a elaboração da hipótese ou hipóteses, como por exemplo:

- Se os gases atmosféricos são responsáveis pela temperatura média na Terra, uma variação da composição desses gases irá alterar a temperatura média global.

- Se o aumento na concentração do $\mathrm{CO}_{2}$ na atmosfera contribui para o aquecimento global, um sistema rico em $\mathrm{CO}_{2}$ deverá aquecer mais do que um sistema com ar atmosférico comum.

O terceiro passo é o teste da hipótese. Porém, para testá-la é preciso planejar a forma de se chegar aos dados e quais os tipos de dados que se pretende obter, como por exemplo temperatura, concentração, $\mathrm{pH}$, pois caso haja falha neste momento os resultados podem não ter utilidade alguma para o objetivo visado.

O planejamento da coleta de dados inicia-se com novas perguntas, pois a hipótese inicial, apesar de nortear o sistema, não dispensa questões capazes de delimitar o aparato experimental.

As seguintes indagações são apenas algumas entre as várias possíveis:

- Por que um ambiente rico em $\mathrm{CO}_{2}$ resultaria em um aquecimento global enquanto o ar não? (Resposta: Porque $\mathrm{o} \mathrm{CO}_{2}$ absorve radiação infravermelha enquanto as principais moléculas do $\operatorname{ar}\left(\mathrm{N}_{2}\right.$ e $\left.\mathrm{O}_{2}\right)$ não a absorve.

- De onde vem a radiação Infravermelha? (Resposta: Da Terra).

- Por que a Terra emite radiação infravermelha (Resposta: Porque converte U.V e U.V.-vis advindos do sol).

Portanto, dessas questões é possível extrair os seguintes requerimentos: Serão necessários dois sistemas sendo que ambos irão precisar de um corpo que mimetize o sol no sentido de emitir U.V. e U.V-vis e de uma superfície que imite a Terra sob o aspecto de absorver U.V. e U.V.-vis e emitir I.V. Para o sistema 1 será necessária uma atmosfera rica em moléculas de $\mathrm{CO}_{2}$ que dificultem a saída dessa radiação, enquanto o sistema 2 deverá se assemelhar a atmosfera comum para vias de comparação.

Então, o planejamento da coleta de dados inicia-se elencando as variáveis explícitas na hipótese, que neste caso são:

- Tipo de radiação;

- Ar atmosférico;

$-\mathrm{CO}_{2}$.

Posteriormente desenha-se a estrutura do experimento a ser realizado levantando suas variáveis e decidindo o tipo de dado que se pretende mensurar:

- Fonte de radiação U.V. e U.V.-vis;

- Material, formato, volume do recipiente para conter o sistema (gás mais superfície);

- Superfície capaz de absorver o U.V. e U.V-vis e converte-los em I.V.;

- Instrumento de medição para acompanhar a variação da temperatura. 
Assim, através do conjunto de variáveis são determinadas aquelas explicitas do sistema. A palavra explícita, neste texto, assume o sentido de "possível perceber", afinal qualquer sistema possui diversas incógnitas, estando em sua maioria ocultas, pois caso fosse possível conhece-las integralmente seria factível se chegar a uma verdade absoluta.

Neste ponto inicia-se a montagem do experimento com posterior coleta de dados e então com os dados em mãos é possível ainda chegar a duas situações:

1) Os dados corroboram com a hipótese;

2) Os dados discordam da hipótese.

Geralmente quando o experimentador, ingênuo, na primeira execução do experimento obtém dados que corroborem suas hipóteses ele se sente satisfeito e finaliza sua investigação. Esse comportamento é equivocado, pois um bom modelo não deve apenas reproduzir o desejado, mas também resistir a testes. Assim, a situação ideal é que o experimentador repita o procedimento garantindo a reprodutibilidade e teste sua hipótese variando os parâmetros pertinentes.

Quando os dados discordam da hipótese o experimentador se vê diante de dois caminhos: 1) reformular sua hipótese podendo considera-la falsa, ou 2) submeter a teste seu arranjo experimental, verificando se as variáveis e todo o aparato utilizado são adequados a proposta visada.

Assim, esses são os princípios básicos gerais para se elaborar um modelo experimental consistente. Não leva-los em consideração pode implicar em premissas falsas que consequentemente levarão a resultados equivocados. Um resumo dos passos para uma atividade investigativa pode ser observado na Figura 2.

Para discutir os experimentos encontrados foi feita a opção por iniciar através de considerações gerais que abarcam todos os experimentos analisados, sendo enfatizados os detalhes dos arranjos experimentais e evitando a repetição sistemática nas discussões. Posteriormente, serão realizadas as considerações pertinentes a cada experimento particular.

Considerações Gerais:

O primeiro ponto para uma modelagem adequada é escolha da radiação luminosa para simular o sol. Em um instante inicial a escolha mais obvia seria ele próprio, entretanto, para utilizá-lo adequadamente seria preciso isolar sua radiação do restante do ambiente, pois ela interage com as moléculas no caminho e com a superfície e todo o entorno onde será situado o aparato experimental.

A radiação solar que chega a superfície da Terra não é quente como intuitivamente tendemos afirmar. A sensação que temos de um aumento da temperatura quando ficamos expostos aos raios solares é resultado da absorção das mesmas pelo nosso corpo que então emite energia térmica. Se chegasse de fato calor do sol na nossa atmosfera, os lugares de maior altitude como o pico do Everest não seriam cobertos de gelo. Portanto quando os autores usam diretamente a luz solar para executar o experimento, eles estão usando toda a radiação térmica emitida pelas superfícies e pelos gases próximos a região onde o experimento está sendo executado. Além disso, caso o mesmo experimento seja 
realizado em altitudes muito diferentes, ou em ambientes diferentes, provavelmente resultariam em dados conflitantes. Logo, a nível de bancada, usar o sol diretamente não é a forma adequada devido a interferência da radiação I.V. advinda do ambiente.

Figura 2- Mapa conceitual de uma atividade investigativa

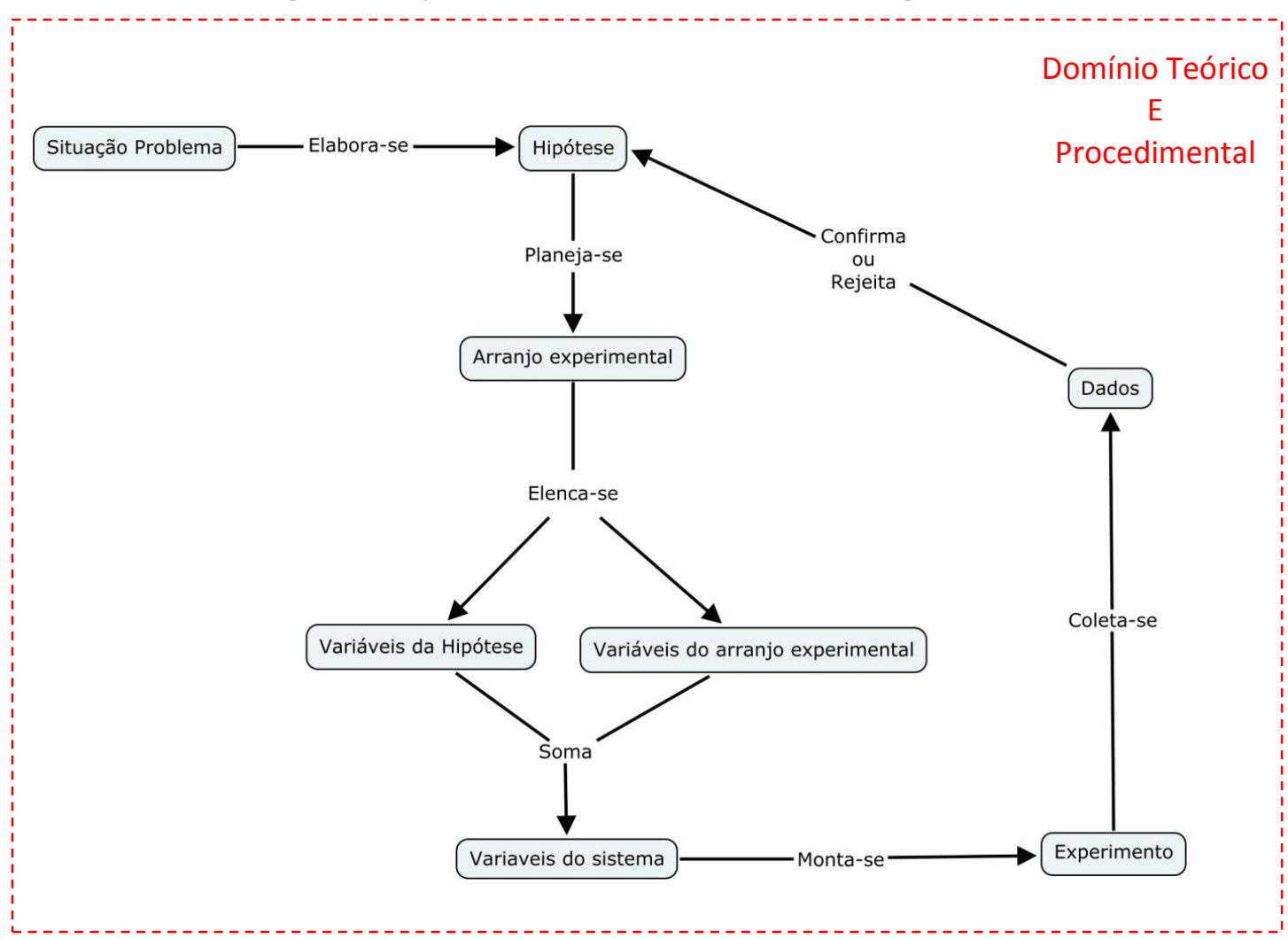

(Fonte: imagem autoral)

Uma segunda fonte de radiação utilizada comumente em experimentos são lâmpadas incandescentes, e esta também é uma escolha equivocada, pois elas emitem principalmente radiação infravermelha ao invés da radiação ultravioleta e UV-vis.

Deste modo uma fonte de luz adequada para mimetizar o sol são lâmpadas que emitem principalmente radiação do tipo UV e/ou UV-vis, o que não foi considerado por nenhum dos experimentos analisados: eles fizeram uso do Sol, de lâmpadas incandescentes e até de uma lâmpada de Infravermelho. Além dos experimentos discutidos neste trabalho, nenhum dos outros localizados na literatura levou em consideração a escolha da radiação de forma pertinente. Sendo assim, pode-se considerar que não há na literatura nenhum experimento capaz de simular o efeito estufa a nível de bancada.

Porém, sendo a proposta desta atividade uma investigação e não uma simples execução tradicional, os alunos podem ser chamados pelo professor mediador a reconhecerem que tais fontes de radiação, por emitirem I.V., estão na verdade simulando a Terra ao invés da radiação solar. 
Além do cuidado com a escolha da radiação outra variável importante a se considerar é a necessidade de um corpo negro dentro do sistema que simule a Terra absorvendo radiação U.V. e U.V.-vis e emitindo infravermelho. Poucos destes experimentos analisados fizeram uso deste corpo, porém, este se tornou desnecessário, pois devido ao tipo de radiação emitida pela lâmpada, esta simula a própria Terra. No entanto, caso os alunos optem por substituir a lâmpada é indispensável que se atente para essa necessidade.

$\mathrm{O}$ Terceiro aspecto fundamental é a presença de $\mathrm{CO}_{2}$ e este traz consigo outras implicações:

- O $\mathrm{CO}_{2}$ utilizado será comercial na forma de gás ou sólido (gelo seco)? Produzido por alguma reação química durante o experimento? Se for produzido por alguma reação, esta se processa interna ou externamente ao sistema?

Estas são algumas das perguntas que o sujeito deve se fazer antes de iniciar a modelagem do sistema, pois essas respostas têm implicações determinantes para a coerência do modelo.

Nos experimentos analisados não foram utilizados reagentes comerciais sólidos ou gasosos. Todos produziram o gás carbônico através da reação entre um ácido (acético ou clorídrico) e bicarbonato de sódio. Alguns conduziram a reação dentro do sistema enquanto outros o fizeram no lado externo. As implicações dessas escolhas resultam em questões físicas e químicas: Quando a reação se processa dentro do sistema os próprios reagentes em excesso ou produtos diferentes do $\mathrm{CO}_{2}$, como a água, podem interferir na mensuração da temperatura. Afinal, a água é um bom absorvedor de calor devido a sua capacidade calorifica. Assim sendo, a situação ideal é que a reação se processe no lado externo. Todavia, mesmo quando a reação é externa ao sistema é importante levar em consideração se o mesmo encontra-se aberto ou fechado, pois um gás sendo inserido em um sistema fechado tem sua pressão elevada pelo aumento da concentração gasosa. Assim, o calor que adentra o sistema pode ter dificuldade em sair não pela absorção da radiação pelos gases, mas sim por uma barreira física ocasionada pela diminuição das correntes de convicção. Uma alternativa para minimizar esses inconvenientes é manter o recipiente aberto, garantindo que a pressão seja equivalente à atmosférica. Outra possibilidade é utilizar um recipiente suficientemente grande para que as correntes de convecção não interfiram no fenômeno que se deseja "observar".

Assim, os erros gerais básicos resumidamente são:

- Fonte inadequada para simular a radiação solar: deve-se usar uma fonte que emita principalmente U.V. e/ou U.V.-vis e caso emita I.V., que seja quantitativamente desprezível;

Ausência de um corpo negro: deve haver um corpo capaz de converter a radiação U.V. e/ou U.V.-vis em I.V.;

- Reação química se processando dentro do sistema: Algum tipo de reação acontecendo dentro do sistema estudado, variando a concentração dos gases ao longo do tempo;

- Sistema fechado: Enquanto injeta-se gás, o ar do sistema inicial fica impossibilitado de sair e assim, a pressão interna (e consequentemente a concentração dos gases) será divergente do recipiente de controle. 
Considerações particulares:

O primeiro experimentos (a) tem praticamente o seguinte protocolo:

Dois recipientes, contendo a mesma quantidade de vinagre e com um termômetro em cada tampa, são expostos a luz solar por aproximadamente 30 minutos, sendo que em um destes é acrescentado bicarbonato de sódio, o qual é fechado rapidamente, resultando em uma temperatura maior na garrafa contendo $\mathrm{NaHCO}_{3}(\mathrm{~s})$ (SOCIETY, 2013)

Neste caso os problemas estão em todas as esferas discutidas anteriormente:

- Fonte inadequada para simular a radiação solar;

- Ausência do corpo negro;

- Reação química se processando dentro do sistema;

- Sistema fechado.

O experimento (b) foi premiado pela Sociedade Brasileira de Química em 2011, e publicado posteriormente na revista virtual de Química (COELHO, BARBALHO, ESCREMIN, 2014). Seu protocolo é basicamente:

Um béquer de $2 \mathrm{~L}$ é preenchido com água até a metade e em seu interior há um termômetro caseiro. Um segundo béquer, também de $2 \mathrm{~L}$ e com um termômetro, é totalmente preenchido com água. Ambos os béqueres são vertidos em uma bacia semipreenchida com água formando uma espécie de Torre de Torriceli. No béquer completamente preenchido é inserida uma mangueira por onde é injetado $\mathrm{CO}_{2}$, que pressiona a coluna de água até que a altura dos gases em ambos os recipientes se iguale. Neste momento a inserção de gás é interrompida, a lâmpada de I.V. é ligada e a temperatura registrada após 20 minutos (Figura 3).

Figura 3- Fotografia original do experimento que objetiva simular o efeito estufa fazendo uso de uma lâmpada de I.V.

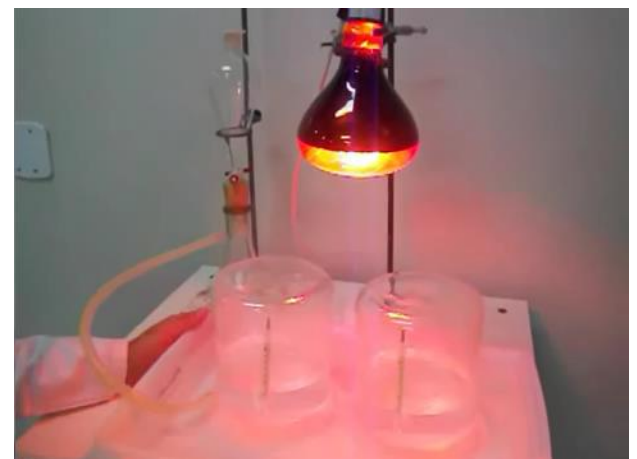

(Fonte: COELHO, BARBALHO E ESCREMIN (2014))

Assim como nos experimentos anteriores os equívocos são:

- Fonte inadequada para simular a radiação solar;

- Ausência do corpo negro,

- Reação química se processando dentro do sistema. 
$\mathrm{O} \mathrm{CO}_{2}$ é produzido através da reação entre o bicarbonato de sódio e o acido acético externamente ao sistema e então através de uma mangueira é direcionado para o béquer completamente preenchido com água. Porém, apesar dos autores alegarem que é o $\mathrm{CO}_{2}$ quem desloca a água no béquer, sendo o $\mathrm{CO}_{2}$ mais denso que o ar é este último que se esvai primeiramente, só em seguida o $\mathrm{CO}_{2}$ irá migrar. Portanto, diferentemente do que acreditam os autores eles não têm um béquer com ar e o outro com o $\mathrm{CO}_{2}$, e sim um com uma mistura mais rica em $\mathrm{CO}_{2}$ do que o outro. Apesar deste equivoco, isto não se configura um problema para o experimento.

Ao se finalizar a reação, a pressão interna dentro dos dois recipientes é equivalente, pois a concentração dos gases é a mesma, já que ambos ocupam o mesmo volume. Entretanto com o decorrer do tempo essa situação vai sendo modificada. Essa alteração resulta da solubilidade do $\mathrm{CO}_{2}$ : Quando o gás é borbulhado no sistema, parte reage com a água produzindo ácido carbônico e alterando o pH do sistema através da seguinte reação :

$$
2 \mathrm{CO}_{2}+\mathrm{H}_{2} \mathrm{O} \longleftrightarrow \mathrm{H}_{2} \mathrm{CO}_{3} \longleftrightarrow \mathrm{H}^{+}+\mathrm{HCO}_{3}^{-}
$$

A mudança do $\mathrm{pH}$ e da natureza da solução, somadas ao aquecimento em um recipiente fechado, altera a pressão de vapor da água. Assim a concentração de gases nos sistemas não é equivalente durante todo o tempo. Além disso, a água tem uma alta capacidade calorifica e, portanto, a sua presença não é só desnecessária como um fator que torna o sistema ainda mais complexo aumentando seu número de variáveis.

Deste modo apesar de ser visualmente interessante a inserção de gás, esse procedimento traz consigo mais problemas do que soluções, principalmente porque a variação de temperatura verificada pelo autor é de $2^{\circ} \mathrm{C}$, ou seja, é uma variação muito pequena diante da complexidade do sistema. Além disso, como o autor usa um termômetro comercial (vendido em farmácia) não é possível mensurar a variação de temperatura entre o estado inicial e final de cada sistema, pois este tipo de termômetro mede apenas temperaturas acima de $35^{\circ} \mathrm{C}$. Assim, é preciso considerar que os termômetros podem estar descalibrados e a variação de temperatura entre os dois sistemas ser apenas resultado da diferença de temperatura inicial dos próprios termômetros ou entre a posição da lâmpada e dos recipientes, pois se um deles estiver recebendo uma maior quantidade de radiação esquentará mais.

O experimento (c) (COSTA, PEDROSO, PRADO, 2007) possui o seguinte aparato experimental:

No interior de um pote de maionese de $2 \mathrm{~kg}$ foi fixada uma lâmpada de tungstênio de $40 \mathrm{~W}$ e um termômetro. A este sistema foi conectado, através de uma mangueira, um Kitassato onde a reação se processou produzindo $\mathrm{CO}_{2}$ (Figura 4).

Segundo os autores, foi feito vácuo no o pote de plástico e a temperatura do recipiente se elevou com o aumento da concentração do gás.

De forma geral os equívocos foram:

- Fonte inadequada para simular a radiação solar;

- Ausência do corpo negro;

- Sistema fechado; 
Além da fonte de radiação ser inadequada, a localização da mesma foi um grande equivoco. A lâmpada dentro do sistema esquenta-o não só pela radiação, mas por efeito Jaule resultante da conversão da energia elétrica em calor. A afirmação de que o recipiente estava a vácuo também está equivocada, pois sendo o recipiente um pote de maionese de plástico esse implodiria pela pressão externa se assim o fosse.

Há também problemas quanto ao gás produzido: A reação se processa externamente ao sistema, porém em uma quantidade ínfima. Além disso, o $\mathrm{CO}_{2}$ é mais denso que o ar e assim, a pouca quantidade de gás produzido irá ocupar o fundo do kitassato prioritariamente, fazendo com que o ar se desloque para o pote de maionese, aumentando então a pressão dentro do sistema em estudo. Os autores alegaram que a temperatura do sistema aumentou com a concentração do $\mathrm{CO}_{2}$ o que não corrobora com os resultados, pois no gráfico apresentado é possível observar que a temperatura para a produção $3 \mathrm{~g}$ de $\mathrm{CO}_{2}$ foi menor do que a temperatura para a produção de 1,5 gramas (Figura 4).

Figura 4- (a)Desenho representacional do aparato experimental na demonstração do efeito estufa e o (b) gráfico com os resultados para diferentes concentrações de $\mathrm{CO}_{2}$ (a)

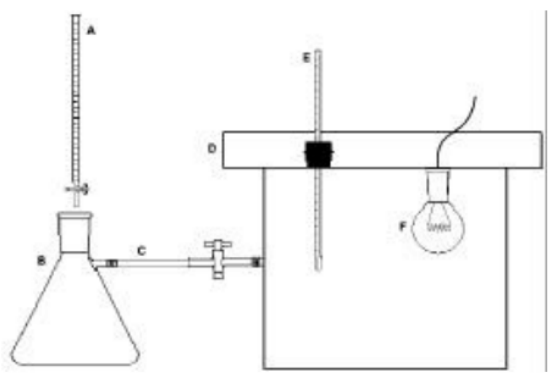

Fig. 1. Esquema do aparato experimental utilizado na demonstração do efeito estufa, confeccionado com uma bureta $(A)$, um kitassato $(B)$, uma torneira $(C)$, um pote usado de maionese de $2 \mathrm{~kg}(\mathrm{D})$, um termômetro (E) uma lâmpada de $40 \mathrm{~W}(\mathrm{~F})$.

(Fonte: COSTA, PEDROSO, PRADO (2007)) (b)

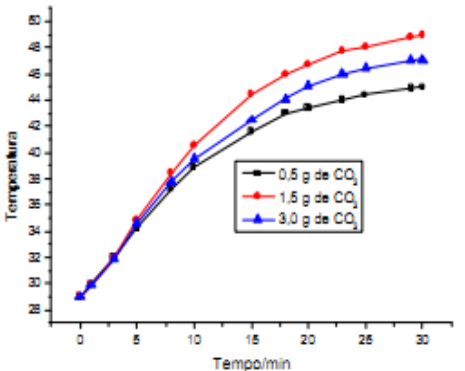

Figura 2 - Variaçăo da temperatura em funçăo do tempo para diversas quantidades de $\mathrm{CO}_{2}$

O experimento (d) (CORDEIRO et al. (2013)) tem o mesmo protocolo do (c) (COSTA, PEDROSO, PRADO (2007)), mas tem como diferença o fato de retirar a lâmpada de dentro do recipiente e substitui-la por uma com maior potência (60W) e trocar o recipiente por um de vidro (Figura 5). Deste modo, os problemas são basicamente os mesmos. Além disso, os autores afirmaram que na tampa foi colocado um isopor não apenas para fixar o termômetro, mas para reduzir as trocas de calor por este ser um bom isolante térmico. Entretanto a área relativa entre a tampa e o vidro do recipiente, que é um bom condutor de calor, é pequena, logo o isolamento é insignificante. 
Figura 5- (a) Foto do aparato experimental utilizado para simular o efeito estufa e (b) o gráfico com os resultados obtidos.

(a)

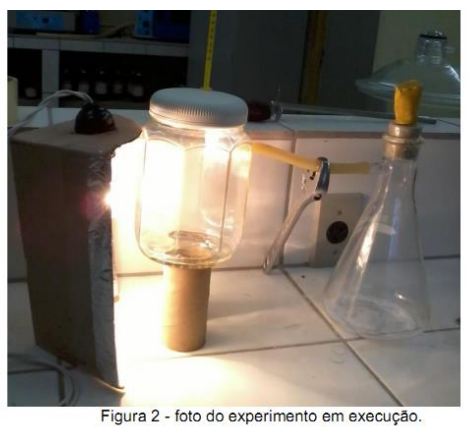

(b)

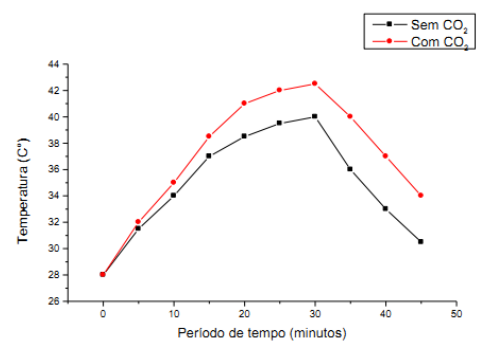

(Fonte: CORDEIRO et al. (2013))

O experimento (e) (SILVA, 2010) encontra-se em alguns sites como no Youtube e tem como protocolo: Em uma garrafa PET se processa uma reação entre ácido acético e bicarbonato de sódio e o $\mathrm{CO}_{2}$ produzido é direcionado para um galão através de uma mangueira. Ambos os recipientes ficam abertos enquanto o gás é vertido em seu interior, sendo que ambos os recipientes são fechados após o final da reação, garantindo que a pressão em ambos seja equivalente. Cada um dos sistemas é iluminado por uma lâmpada incandescente, tendo suas temperaturas monitoradas. Como resultado, a temperatura é maior no recipiente que contém $\mathrm{CO}_{2}$ (Figura 6).

Figura 6.- Frames capturados do site Youtube para representar o (a) experimento exposto para simular o efeito estufa e (b) os dados obtidos.

(a)

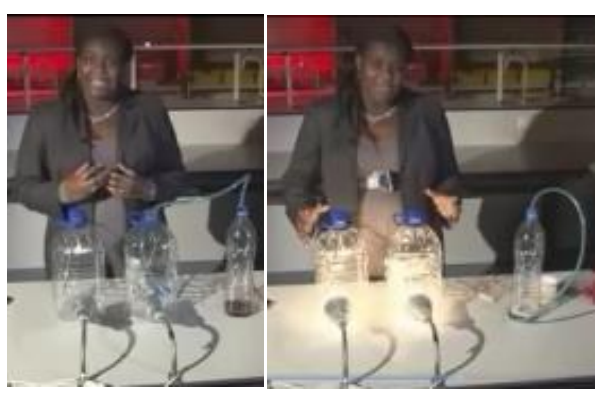

(b)

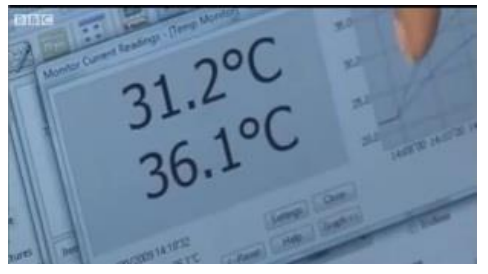

(Fonte: SILVA (2010)).

Dentre todos os experimentos até aqui apresentados, este foi o que levou em consideração um maior número de fatores, apesar de não ser um simulador do efeito estufa, pois: 1) não faz uso de um emissor de radiação adequado e 2) nem de um corpo negro. Ele positivamente realiza a reação de produção de $\mathrm{CO}_{2}$ externamente ao sistema, mantendo-o aberto e assim garantindo equidade entre a pressão nos recipientes.

Chama atenção neste protocolo o fato da autora ter utilizado 2 luminárias ao invés de uma, o que aumenta a possibilidade de a radiação incidida nos sistemas não ser equivalente. Além disso, não foi feita uma referência sobre a quantidade de reagentes usados e assim não é possível saber se o volume de gás produzido foi suficiente para deixar a garrafa de reação e preencher o sistema monitorado. 
No experimento (f) (Figura 7) são inseridos uniformemente, em dois aquários de 19 litros, um substrato escuro (areia preta ou rochas de aquário). Sobre o substrato é colocado um prato, de vidro ou material escuro, onde deve haver vinagre. Em um dos pratos é adicionado bicarbonato de sódio para que produza $\mathrm{CO}_{2}$. Uma luminária, com lâmpada de pelo menos $150 \mathrm{~W}$, é acesa sobre cada um dos aquários e a temperatura é monitorada (LUEDDECKE; PINTER; MCMANUS 2001).

Figura 7- (a) Desenho representacional do aparato experimental e (b) os dados obtidos.

(a)

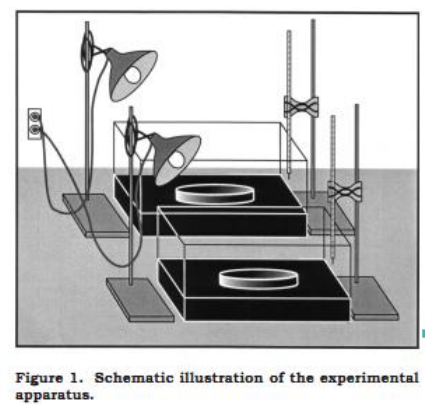

(Fonte: LUEDDECKE; PINTER; MCMANUS (2001)) (b)

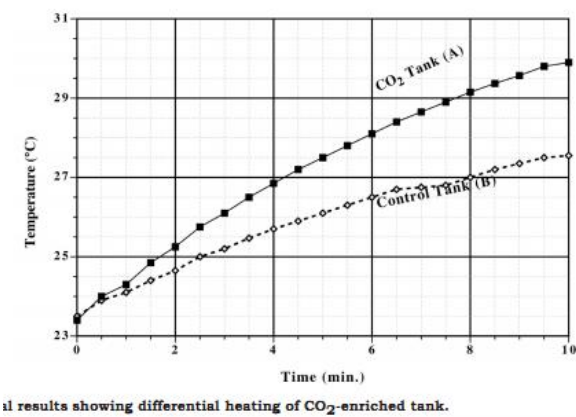

11 results showing differential heating of $\mathrm{CO}_{2}$-enriched tank.

Assim, de forma geral os problemas são:

- Fonte inadequada para simular a radiação solar;

- Reação dentro do sistema;

Como no experimento anterior, os autores também optaram por fazer uso de duas lâmpadas ao invés de uma que iluminasse os dois sistemas; além disso, inicialmente a intenção era fazer uso de um sistema fechado, mas como os resultados não foram os esperados optaram por manter o sistema aberto e infelizmente se omitiram de tentar explicar os dados contraditórios, o que evidência um interesse maior no resultado final em detrimento dos conceitos.

No experimento (g) (KEATING, 2007) uma lata de Coca-Cola, após agitação vigorosa para retirada do $\mathrm{CO}_{2}$ foi inserida em uma garrafa PET de $2 \mathrm{~L}$, enquanto uma segunda lata teve seu conteúdo vertido lentamente para minimizar a perda do gás. Ambas foram posicionadas sob a luz solar com o cuidado de se situarem sobre o mesmo anteparo. Como resultado, a garrafa contendo maior quantidade de gás atingiu uma temperatura maior (Figura 8).

Portanto, o experimento apresenta os seguintes problemas :

- Fonte inadequada para simular a radiação solar;

- Reação dentro do sistema;

- Sistema fechado;

Apesar da presença do absorvente escuro, sendo a fonte de radiação inadequada não é possível afirmar que a quantidade de energia dentro do sistema é resultado da entrada de U.V. e U.V.-vis com posterior conversão em I.V ou se resulta de uma maior entrada do I.V. externo. Além disso, como não há forma de garantir que todo $\mathrm{CO}_{2}$ se esvaeceu do liquido, ao colocá-lo para aquecer 
mais gás pode ter sido dissipado já que a solubilidade é inversamente proporcional a temperatura. Assim os resultados podem estar correlacionados com a diferença de concentração dos gases, sejam eles quais forem, já que os recipientes se encontram fechados.

Figura 8- (a) Demonstração da execução do experimento e (b) os dados obtidos.

(a)

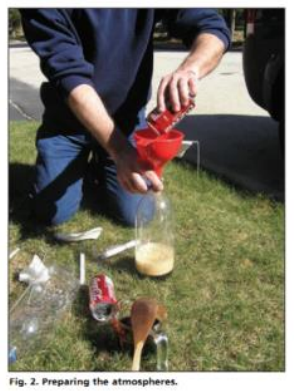

(b)

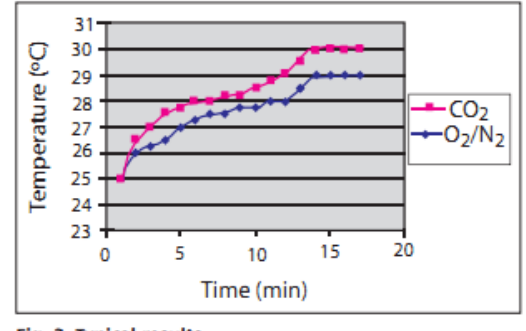

Fig. 3. Typical results.

(Fonte: KEATING, 2007)

Os Experimentos (h) (ADELHELM; HÖHN; FRANZ, 1993) e (i) (LISTER, 1995) apresentam basicamente o mesmo protocolo:

Figura 9- Desenhos do aparato experimental (a) h e (b) i

a)

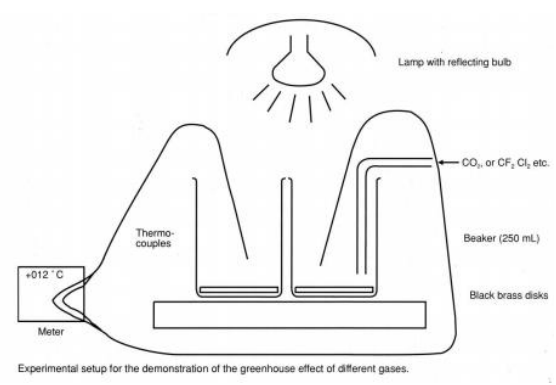

b)

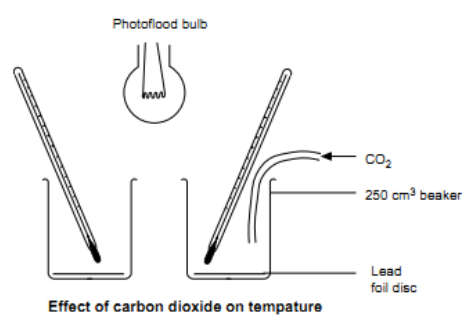

(Fonte: (a) ADELHELM, HÖHN; FRANZ, 1993 e (b) LISTER, 1995)

Dois béqueres contendo um disco com uma superfície preta opaca, sendo em um destes injetado $\mathrm{CO}_{2}$, têm sua temperatura acompanhada enquanto são expostos a radiação de uma lâmpada incandescente. Ambos os béqueres permanecem abertos durante toda a mensuração no intuito de manter a pressão constante.

De forma geral, o único equívoco desta metodologia foi a escolha inadequada da radiação. Como consequência não é possível especular se o aumento da temperatura é advindo da absorção de infravermelho incidido ou se há de fato a conversão entre os comprimentos de onda. Para clarear esta hipótese, a substituição das lâmpadas deveria ser adotada. Além disso, para submeter tal experimento a teste, seria recomendável a repetição do procedimento com ar atmosférico e com $\mathrm{CO}_{2}$, em ambos os recipientes, para verificar a adequação do uso de termômetros ou termopares para esta configuração e sensibilidade de experimento. Seria aconselhável também a repetição com gases que não absorvam I.V., como o oxigênio e o argônio, pois 
caso nestas situações ainda seja possível observar uma variação de temperatura, esta pode ser resultado das correntes de convecção.

Um resumo dos fatores mais importantes a serem levados em consideração em experimentos que visam simular o efeito estufa pode ser observado na Tabela 1, juntamente com o que foi levado em consideração em cada um destes experimentos.

Tabela 1- Fatores gerais a serem levados em consideração em um sistema que pretende simular o efeito estufa. $X=$ Experimento não levou em consideração o fator; $\vee$ = O experimento levou em consideração o fator.

\begin{tabular}{llllllllll} 
Fatores Gerais & $\mathrm{A}$ & $\mathrm{B}$ & $\mathrm{C}$ & $\mathrm{E}$ & $\mathrm{F}$ & $\mathrm{G}$ & $\mathrm{H}$ & $\mathrm{I}$ & $\mathrm{J}$ \\
\hline "Sol" inadequado & $\mathrm{X}$ & $\mathrm{X}$ & $\mathrm{X}$ & $\mathrm{X}$ & $\mathrm{X}$ & $\mathrm{X}$ & $\mathrm{X}$ & $\mathrm{X}$ & $\mathrm{X}$ \\
"Terra" inadequada & $\mathrm{X}$ & $\mathrm{X}$ & $\mathrm{X}$ & $\mathrm{X}$ & $\mathrm{X}$ & $\mathrm{V}$ & $\mathrm{V}$ & $\mathrm{V}$ & $\mathrm{V}$ \\
Reação dentro do sistema & $\mathrm{X}$ & $\mathrm{X}$ & $\mathrm{V}$ & $\mathrm{V}$ & $\mathrm{V}$ & $\mathrm{X}$ & $\mathrm{X}$ & $\mathrm{V}$ & $\mathrm{V}$ \\
Concentração de gases diferentes & $\mathrm{X}$ & $\mathrm{X}$ & $\mathrm{X}$ & $\mathrm{X}$ & $\mathrm{V}$ & $\mathrm{V}$ & $\mathrm{X}$ & $\mathrm{V}$ & $\mathrm{V}$
\end{tabular}

Portanto, através dos experimentos expostos é possível perceber o grande número de equívocos que poderiam ter sido evitados caso os autores se questionassem mais sobre a teoria em questão ao invés de simplesmente terem como objetivo realizar a simulação do modelo. Outro ponto crucial na investigação científica e que deveria fazer parte na elaboração de um experimento, seja ele para fins didáticos ou de pesquisa, é a submissão a testes. Um modelo para ser adequado não deve apenas funcionar bem em uma única condição, mas deve responder de forma previsível quando parâmetros conhecidos forem variados. Assim se os autores substituíssem as lâmpadas, o tipo de gás e a concentração destes, poderiam ter detectado problemas em seu protocolo. Deste modo, é necessário enfatizar que apenas a criação da hipótese, apesar de sua extrema importância no método investigativo, não é suficiente, pois embora sua função seja nortear a elaboração do modelo ela não deve ser a única questão, mas o inicio que irá auxiliar a elaboração de várias outras perguntas a posteriori. É crucial que se tenha cuidado para que produto final não torne preterido todo o processo, afinal em todos os experimentos analisados neste trabalho os autores garantiram terem obtido bons resultados numéricos, porém como foi discutido nenhum deles de fato simula o efeito estufa, o que poderia ter sido evitado ao enfatizar o percurso para se chegar aos dados finais através de um número razoável de perguntas para o sistema, tentando extrair do laboratório um número maior de respostas ao invés de "arrancar" do sistema "a resposta".

\section{CONCLUSÃO}

A atividade prática na sala de aula não visa formar mini cientistas, mas cidadãos críticos hábeis em analisar, fazer ponderações e, portanto, capazes de elencar as variáveis explicitas que são importantes em um processo. Deve-se atentar para o fato de que mesmo conhecendo um número razoável de variáveis nunca haverá certeza sobre a totalidade delas. Portanto, um experimento bem modelado deve minimizar fatores desnecessários, como a presença de água dentro do sistema, e controlar o que for possível. 
Enfim, a intenção deste trabalho não era chamar atenção exclusivamente para o efeito estufa, mesmo considerando este um tema importante na sala de aula, mas chamar atenção para a forma de se elaborar uma atividade do tipo investigativa e o fato de que existem vários experimentos na literatura e na internet que alegam tratar de determinado fenômeno quando na verdade desconsideraram tantos fatores que descaracterizaram o objetivo inicial. Essas premissas levam a um outro aspecto discutido por Thomas Kuhn (1998): a necessidade de se avaliar uma informação por ela mesma e não apenas por quem a propagou.

Os experimentos aqui citados podem ser utilizados pelos professores em sala de aula, desde que se atentem a discutir com os alunos os equívocos e limites de cada um deles e não apenas os utilizem para fins ilustrativos. Na análise da atividade experimental, seja na ciência ou no processo educativo, a coerência deve preponderar sobre o produto. Entender como o pensamento cientifico é elaborado e desenvolver o pensamento crítico devem ser objetivos mais importantes do que simplesmente tornar a aula diferente por meio da realização de experimentos. 


\title{
The investigative activity in the preparation and analysis of teaching experiments
}

\begin{abstract}
The experimental activity can be a great resource to motivate and broaden the spectrum of learning, but this should bring more than colors and ostentatious changes, should help the student to assume its role as one's own learning agent stimulating autonomy, reflection and critical thinking. The research methodology is the most appropriate consensus, resulting in a major improvement in procedural and cognitive skills by requiring the student from a problem situation develop a hypothesis, plan a methodology, obtain data and place them on trial, confirming it or rejecting it. In light of the qualities of investigative activity that this work proposes to demonstrate how it is possible, through general principles, develop and test experimental models avoiding basic mistakes. The experiments used as a model intended to mimic the greenhouse effect and the absence of criteria was found that none of the activities were successful.
\end{abstract}

KEYWORDS: Greenhouse experiments. Investigative. 


\section{REFERÊNCIAS}

ADELHELM, M.; HÖHN, E.-G.; FRANZ, D.A. A simple demonstration of the greenhouse effect. Jornal of chemical education, v.70, n.1, p.73-74, 1993.

ATAIDE, M. C. E. S.; SILVA, B. V. C. As metodologias de ensino de ciência: contribuiç̧̃̃es da experimentação e da história e filosofia da ciência. Holos ${ }_{2}$ v.4, n.27, p.171-182, 2011.

BENITE, A.M.C.; BENITE, C.R.M. O laboratório didático no ensino de química: uma experiência no ensino público brasileiro. Revista Iberoamericana de Educación, v.2, n.48, p.1-10, 2009.

BORGES, A.T. Novos Rumos para o laboratório escolar de ciências. Caderno Brasileiro de Ensino de Física, v.19, n.3, p.291-314, 2002.

CHALMERS, A. A fabricação da ciência. São Paulo: UNESP, 1994.

COELHO, A.; BARBALHO, E.S.; ESCREMIN, J.V. Desenvolvimento de um experimento sobre o efeito estufa: uma proposta para o ensino. Revista virtual de química, v.6, n.1, p.142-151, 2014.

CORDEIRO, D. O.; SILVA, J. E.; ALMEIDA, C.L.A.; MARTINS, J.S. Simulação e avaliação do efeito estufa a partir da adição da $\mathrm{CO}_{2}$ em um sistema fechado. 2013. Trabalho apresentado no $5^{\circ}$ Congresso Norte-Nordeste de Química, Natal, 2013.

COSTA, L.L.; PEDROSO, C.P.; PRADO, A.G.S. Experimento didático para demonstração do efeito estufa. 2007. Trabalho apresentado na $30^{a}$ Reunião anual da sociedade Brasileira de Química, Águas de Lindóia, 2007.

FILHO, J.P.A. Regras da transposição didática aplicadas ao laboratório didático. Caderno Catarinense de Ensino de Física, v.17, n.2, p.44-59, 2000.

GIOPPO, C.; SCHEFFER, E.W.O.; NEVES, M.C.D. O ensino experimental na escola fundamental: uma reflexão de caso no Paraná. Educar, v.14, p.39-58, 1998.

GIORDAN, M. O papel da Experimentação no ensino de ciência. Química Nova na Escola, v.2, n.10, p.43-50, 1999. 
GOI, M.E.J.; SANTOS, F. M. T. Resolução de problemas e atividades experimentais no ensino de química. 2008. Trabalho apresentado no XIV Encontro nacional de ensino de química, Curitiba, 2008.

GONÇALVES, F.P.; MARQUES, C.A. A problematização das atividades experimentais na educação superior em química: uma pesquisa com produções textuais docentes-Parte II. Química Nova, v.35, n.4, p.837-844, 2012.

KEATING, C.F. A simple experiment to demonstrate the effects of greenhouse gases. The physics teacher, v.45, n.6, p.376-378, 2007.

KUHN, T. S. A estrutura das Revoluções científicas. São Paulo: Perspectiva, 1998.

LABURU, C.E.; BARROS, M.A.; KANBACH, B.G. A relação com o saber profissional do professor de física e o fracasso da implementação de atividades experimentais no ensino médio. Investigação em ensino de ciências, v.12, n.3, p.305-320, 2007.

LISTER, T. Classic Chemistry Demonstrations. London: The royal society of chemistry, 1995.

LUEDDECKE, S.B.; PINTER, N.; MCMANUS, S.A. Journal of Geoscience Education, v.49, n.3, p.274-279, 2001

MUNFORD, D.; LIMA, M.E.C.C. Ensinar ciências por investigação: em quê estamos de acordo? Ensaio Pesquisa em Educação em Ciências, v.9, n.1, p.1-23, 2007.

PÉREZ,D.G.; MONTORO, I.F.; ALÍS, J.C.; CACHAPUZ, A.; PRAIA, J. Para uma imagem não deformada do trabalho científico. Ciência \& Educação, v.7, n.2, p.125-155, 2001.

SILVA, R.C. (2010). Experiência que demonstra efeito de estufa. Disponível em: $<$ http://www.esquerda.net/content/experi\%C3\%AAncia-que-demonstra-efeitode-estufa>. Acesso 20 de maio 2014.

SILVA, R.T.; CURSINO, A.C.; AIRES, J.A.; GUIMARÃES, O.M. Contextualização e experimentação uma análise dos artigos publicados na seção "experimentação no ensino de química" da revista química nova na escola 2000-2008. EnsaioPesquisa em Educação em ciências, v.11, n.2, p.1-22, 2009. <http://www.metlink.org/wp-content/uploads/2013/10/greenhouse.pdf>. Acesso 20 de maio 2014. 
SUART, R.C. Habilidades cognitivas manifestadas por alunos do ensino médio de química em atividades experimentais investigativas. 2008. 218f. Dissertação (Mestrado em Ensino de Ciências) - Universidade de São Paulo, São Paulo, 2008.

SUART, R.C.; MARCONDES, M.E.R. A manifestação de habilidades cognitivas em atividades experimentais investigativas no ensino médio de química. Ciência \& Educação, v.14, n.1, p.50-75, 2009.

THOMAZ, M.F. A experimentação e a formação de professores de ciências: uma reflexão. Caderno Catarinense de Ensino de Física, v.17, n.3, p.360-370, 2000.

ZOMPERO, A.F.; LABURU, C.E. Atividades investigativas no ensino de ciências: aspectos históricos e diferentes abordagens. Ensaio-Pesquisa em Educação em ciências, v.13, n.3, p.67-81, 2011. 
Recebido: 04 mar. 2015

Aprovado: 06 jun. 2016.

DOI: http://dx.doi.org/10.3895/rbect.v9n2.2805

Como citar:

TOLEDO, E. J. L.; FERREIRA, L. H. A atividade investigativa na elaboração e análise de experimentos didáticos. Revista Brasileira de Ensino de Ciência e Tecnologia, v. 9, n. 2, 2016. Disponível em:

<https://periodicos.utfpr.edu.br/rbect/article/view/2805>. Acesso em: xxx.

Correspondência:

Evelyn Jeniffer de Lima Toledo

Rodovia Washington Luís, 310, São Carlos-SP, CEP: 13565-905

Luiz Henrique Ferreira

Rodovia Washington Luís, 310, São Carlos-SP, CEP: 13565-905

Direito autoral: Este artigo está licenciado sob os termos da Licença Creative Commons-Atribuição 4.0

Internacional. 